\title{
NGHIÊN CỨU GIÁ TRI SIÊU ÂM ĐÀN HỒI SÓNG BIẾN DẠNG TRONG CHẨN ĐOÁN UNG THƯ VÚ
}

\author{
Nguyễn Văn Hoàng*, Lưu Vũ Dũng*, Vũ Văn Tâm*
}

TÓM TẮT

Mục tiêu: Đánh giá giá trị chẩn đoán ung thư vú của phương pháp siêu âm đàn hồi sóng biến dạng Shear wave elastography (SWE). Đối tượng và phương pháp: Nghiên cứu trên 60 bệnh nhân nữ với 62 khối u vú được siêu âm bằng $B$ - mode, phân loai BI-RADS 3, 4a/b/c, 5; được siêu âm đàn hồi sóng biến dang để đánh giá về mặt định lượng độ cứng của khối u thông qua giá trị vận tốc sóng biến dạng $(\mathrm{m} / \mathrm{s})$. Từ đó đánh giá độ nhạy, độ đặc hiệu, ngưỡng cut-off của phương pháp siêu âm này trong chẩn đoán u vú lành, ác tính. Kết quả: 60 bệnh nhân nữ có u vú (47 lành tính, 15 ung thu vú được chẩn đoán xác định bằng mô bệnh học). Giá trị trung bình về vân tốc sóng biến dạng của các tổn thương lành tính là $2,61 \pm 0,52 \mathrm{~m} / \mathrm{s}$ và ác tính là $5,85 \pm 1,18 \mathrm{~m} / \mathrm{s}$. Diện tích dưới đường cong ROC (AUC) là 0,997. Vận tốc trung bình ở ngướng cắt $3,79 \mathrm{~m} / \mathrm{s}$ có độ nhay $100 \%$ và độ đặc hiệu 95,7\%. Kết luận: Siêu ẩm đàn hồi sóng biến dạng hứa hẹn là kỹ thuật có độ nhạy, độ đặc hiệu cao trong chẩn đoán các tổn thương vú, rất hữu ích trong việc phân biệt tổn thương ác tính và lành tính của tuyến vú.

Tư khóa: tổn thương vú, chẩn đoán, siêu âm B mode, siêu âm đàn hồi, ung thư vú.

\section{SUMMARY \\ VALUE OF SHEAR WAVE ELASTOGRAPHY IN DIAGNOSIS OF BREAST CANCER}

Objective: The purpose of this study was to evaluate the value of shear wave elastography (SWE) in diagnosis of benign and malignant breast lesions. Methods: 60 women with 62 breast tumors were evaluated by B - mode ultrasound and shear wave elastoqraphy. The breast lesions were classified by US breast imaging reporting and data system (BI-RADS) category $3,4 a / b / c, 5$. The maximum, minimum, mean and median shear wave velocity (SWV) values in the lesions were obtained. From that, evaluated the sensitivity, specificity and cut - off of the shear wave elastography for diagnosis of benign and malignant breast lesions. Results: 60 women with 62 breast lesions, diagnosed by histopathology. Fifteen of 62 lesions were malignant and 47 were benign. The mean SWV $(5.85 \pm 1.18 \mathrm{~m} / \mathrm{sec}$ vs $2.61 \pm 0.52 \mathrm{~m} \mathrm{~m} / \mathrm{sec}$ ) for malignant lesions and benign lesions. The cut-off value of mean SWV was $3.79 \mathrm{~m} / \mathrm{s}$, with sensitivity and specificity of $100 \%$ and $95.7 \%$ respectively. Conclusion: Using SWE with high sensitivity, specificity in diagnosis of benign and malignant breast lesions. SWE is useful in

*Bênh viên Phu sản Hải Phòng

Chịu trách nhiệm chính: Vũ Văn Tâm

Email: Drvuvantam@gmail.com

Ngày nhâan bài: 9.11 .2020

Ngày phản biện khoa học: 21.12.2020

Ngày duyệt bài: 30.12.2020 differentiating malignant from benign breast lesions.

Keywords: Breast lesion, B - mode ultrasound, shear ware elastogrphy, breast cancer.

\section{I. ĐẶT VẤN ĐỀ}

Trên thế giới, ung thư vú là nguyên nhân hàng đâu gây tử vong ở phụ nữ [3]. Năm 2017, ước tính khoảng 252710 phụ nữ bị ung thư vú xâm lấn mới được chẩn đoán và khoảng 40610 người đã chết vì loại ung thư này [1].

Ở Việt Nam, tỳ lệ ung thư vú tăng lên đều đặn trong các thập kỷ qua với tỷ lệ 13,8/100000 phụ nữ năm 2000, đến năm 2010, tỷ lệ này là 28,1/ 100000 phụ nữ [5].

Trong những năm gần đây, siêu âm đàn hồi được phát triển mạnh mẽ. Nhiều kết quả nghiên cứu cho thấy siêu âm đàn hồi giúp chẩn đoán phân biệt tổn thương vú lành tính và ác tính [2],[4]. Các khối u vú ác tính có xu hướng cứng hơn các tổn thương lành tính, và siêu âm đàn hồi cũng được báo cáo góp phân cải thiện độ đặc hiệu cho chẩn đoán các khối u vú đặc khi siểu âm B - mode [7]. Siêu âm đàn hồi sóng biến dạng đã được nhiều tác giả nước ngoài nghiên cứu nhưng tại Việt Nam chưa được nghiên cứu nhiêu.

Do đó chúng tôi thực hiện nghiên cứu này dùng phương pháp siêu âm đàn hồi sóng biến dạng SWE để khảo sát khối u vú. Kết quả thể hiện độ cứng của khối u qua giá trị vận tốc sóng biến dạng $(\mathrm{m} / \mathrm{s})$. Mục tiêu nghiên cưuu: Đánh giá giá trị chân đoán ung thư vú của phương pháp siêu ầm đàn hồi sóng biến dạng.

\section{II. ĐỐI TƯỢNG VÀ PHƯƠNG PHÁP NGHIÊN CỨU}

1. Đối tượng nghiên cứu. Nghiên cứu thực hiện trên 60 bệnh nhân nữ với 62 khối u vú đến khám tại Bệnh viện Phụ sản Hải Phòng, từ tháng 10/2018 đến tháng 6/2019.

*Tiêu chuẩn lựa chọn: (i) Tất cả phụ nữ đi khám vú ở bệnh viện Phụ sản Hải Phòng, phát hiện khối u bất thường ở vú được xếp loại BIRADS 3,4,5 trên siêu âm B - mode. (ii) Có đầy đủ kết quả khám lâm sàng, siêu âm B - mode, siêu âm đàn hồi, có kết quả mô bệnh học sau phẫu thuật. (iii) Bệnh nhân tình nguyện tham gia nghiên cứu

*Tiêu chuẩn loại trừ: (i) Tổn thương đã được chẩn đoán ung thư vú, (ii) Bệnh nhân đã có can thiệp phẫu thuật hoặc làm thẩm mỹ vùng ngực. (iii) Phụ nữ mang thai, phụ nữ đang nuôi con bằng sữa mẹ.

2. Thời gian và địa điểm nghiên cứu: Từ 
tháng 10/2018 đến tháng 6/2019 tại bệnh viện Phụ sản Hải Phòng

\section{Phương pháp nghiên cứu}

- Thiết kế nghiên cứu: mô tả tiến cứu

- Phương pháp chọn mẫu: Chọn mẫu thuận tiện không xác suất trong thời gian nghiên cứu từ $1 / 10 / 2018$ đến hết $30 / 6 / 2019$ thỏa mãn các tiêu chuẩn lựa chọn và loại trừ.

- Phương tiện nghiên cứu: Máy siêu âm ACUSON S2000 ABVS của Siemens, đầu dò thẳng tần số 4-9MHz.

\section{KẾT QUẢ NGHIÊN CỨU}

- Tuổi trung bình của nhóm nghiên cứu là $38,9 \pm 13,8$ tuổi, trong đó thấp nhất 19 tuổi, cao nhất 76 tuổi. Người mắc ung thư vú trẻ nhất là 34 tuổi, cao nhất là 76 tuổi. Nhóm tuổi 50-59 tuổi có tỷ lệ mắc ung thư vú cao nhất $(33,3 \%)$.

- Lý do thường gă̆p nhất khi bệnh nhân đến viện là tự sờ thây khối $u$ bất thường trong vú $(66,1 \%)$. Một lý do khác mà bệnh nhân đến khám là dấu hiệu đau vú $(19,4 \%)$, đi khám định kỳ $(12,9 \%)$. Một bênh nhân vào viện khám vừa sờ thấy $u$ và kèm đau, chiếm $1,6 \%$.

- Kết quả mô bệnh học: 100\% tổn thương đều được chẩn đoán xác định bằng kết quả mô bệnh học sau phẫu thuật, có 47 tổn thương lành tính đều là u xơ tuyến vú, chiếm $75,8 \%$, và 15 tổn thương ác tính, đều là ung thư biểu mô tuyến, chiếm $24,2 \%$.

Bảng 1: Phân loại BI- RADS trên siêu âm $B$ - mode

\begin{tabular}{|c|c|c|}
\hline \multirow{2}{*}{$\begin{array}{c}\text { Phân loại } \\
\text { BI-RADS }\end{array}$} & \multicolumn{2}{|c|}{ Siêu âm B - mode } \\
\cline { 2 - 3 } & Số lượng (n) & Tỷ lệ (\%) \\
\hline 3 & 30 & 48,4 \\
\hline $4 a$ & 16 & 25,8 \\
\hline $4 b$ & 6 & 9,7 \\
\hline $4 c$ & 1 & 1,6 \\
\hline 5 & 9 & 14,5 \\
\hline Tống & $\mathbf{6 2}$ & $\mathbf{1 0 0}$ \\
\hline
\end{tabular}

Nhận xét: Tốn thương BIRADS 3 chiếm tỷ lệ cao nhất 48,4\%, tiếp đến BI-RADS 4 (chiếm $37,1 \%)$, thấp nhất BI-RADS 5, chiếm 14,5\%.

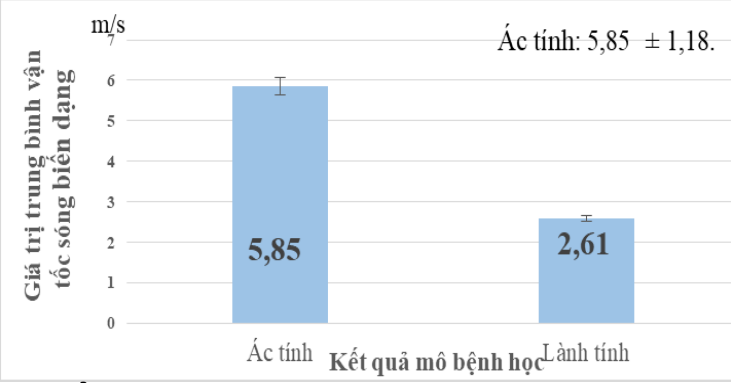

Biểu đồ 1. Giá trị trung bình vận tốc sóng biến dạng của tổn thương lành, ác tính
Nhận xét: Các tổn thương ác tính có vận tốc sóng biến dạng trung bình là $5,85 \pm 1,18 \mathrm{~m} / \mathrm{s}$, cao hơn hẳn ở nhóm lành tính, là $2,61 \pm 0,52 \mathrm{~m} / \mathrm{s}$.

Từ số liệu vận tốc sóng biến dạng của u vú, chúng tôi có biểu đồ về đường cong ROC.

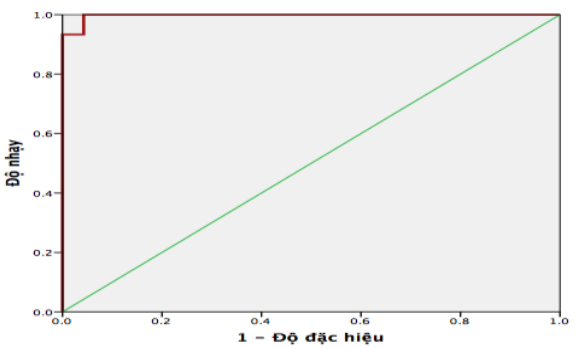

Biểu đồ 2. Đường cong ROC của vân tốc sóng biến dạng trong chẩn đoán u vú ác tính

Nhân xét: Diện tích dưới đường cong ROC (AUC) là 0,997.

Bảng 1. Các ngưỡng giá trị tham chiêu của vận tốc sóng biến dạng trong chẩn đoán u vú ác tính.

\begin{tabular}{|c|c|c|}
\hline $\begin{array}{c}\text { Vận tốc sóng biến } \\
\text { dạng (m/s) }\end{array}$ & $\begin{array}{c}\text { Độ nhạy } \\
(\mathbf{\%})\end{array}$ & $\begin{array}{c}\text { Độ đă̆c } \\
\text { hiệu (\%) }\end{array}$ \\
\hline 3,19 & 100 & 91,5 \\
\hline 3,42 & 100 & 93,6 \\
\hline 3,79 & 100 & 95,7 \\
\hline 3,98 & 93,3 & 95,7 \\
\hline 4,13 & 93,3 & 100 \\
\hline
\end{tabular}

Nhận Xét: Vận tốc sóng biến dạng ở ngưỡng giá trị tham chiếu $3,79 \mathrm{~m} / \mathrm{s}$ có độ nhạy $100 \%$ và độ đặc hiệu $95,7 \%$ cao nhất trong chẩn đoán u vú ác tính.

\section{BÀN LUÂ̂N}

- Tuổi trung bình của nhóm nghiên cứu là $38,9 \pm 13,8$ tuổi, trong đó thấp nhất 19 tuổi, cao nhất 76 tuổi. Người mắc ung thư vú trẻ nhất là 34 tuổi, cao nhất là 76 tuổi. Nhóm tuổi 50 - 59 tuổi có tỷ lệ mắc ung thư vú cao nhất $(33,3 \%)$.

- Lý do thường gặp nhất khi bênh nhân đến viện là tự sờ thấy khối u bất thường trong vú $(66,1 \%)$. Các lý do khác là dấu hiệu đau vú $(19,4 \%)$, đi khám định kỳ (12,9\%). Một bệnh nhân vào viện khám vừa sờ thấy $u$ và kèm đau, chiếm 1,6\%. Do đó, nếu một phụ nữ tự phát hiện thấy khối u tại vú, dù đau hay không đau cũng cần đi khám ngay

- Tất cả các tổn thương đều được chẩn đoán xác định bằng kết quả mô bệnh học sau phẫu thuật, có 47 tổn thương lành tính đều là u xơ tuyển vú, chiếm $75,8 \%$, và 15 tổn thương ác tính, đều là ung thư biểu mô tuyến, chiếm 24,2\%.

- Giá trị vận tốc sóng biến dạng của khối u vú. Sóng siêu âm truyền trong mô là sóng 
doc, với vận tốc trung bình $1540 \mathrm{~m} / \mathrm{s}$. Khi truyền đến tổn thương, sóng biến dạng là sóng ngang. Vận tốc sóng biến dạng ngang từ $0-10 \mathrm{~m} / \mathrm{s}$.

Với kỹ thuật siểu âm đàn hồi định lượng (SWE), sóng biến dạng ngang được tạo ra bởi xung lực bức xạ âm (ARFI - Acoustic radiation force impulse). Sóng này lan truyền trong mô cứng sẽ nhanh hơn mô mềm [6].

Nghiên cứu của chúng tôi, vận tốc sóng biến dạng của các tổn thương lành tính có giá trị nhỏ nhất, lớn nhất và trung bình lần lượt là $1,44 \mathrm{~m} / \mathrm{s}$, $3,99 \mathrm{~m} / \mathrm{s}$ và $2,61 \pm 0,52 \mathrm{~m} / \mathrm{s}$. Các tổn thương này đều được chẩn đoán xác định dựa vào mô bệnh học sau mổ cho kết quả là u xơ tuyến vú. Đây là tổn thương u vú lành tính hay gặp nhất và có độ đàn hồi tương đối mềm.

Ngược lại, các khối ung thư vú thường có xu hướng cứng nên vận tốc sóng biến dạng tương đối cao. Trong nghiên cứu này, một số khối ung thư biểu mô tuyến có vận tốc sóng biến dạng rất cao, cao nhất $8,57 \mathrm{~m} / \mathrm{s}$, cho thấy khối ung thư vú này rất cứng, đặc biệt các khối ung thư có thời gian bị bệnh lâu và có vôi hóa trong u. Nghiên cứu chúng tôi cho thây các tổn thương ác tính có các giá trị nhỏ nhất, lớn nhất và giá trị trung bình về vận tốc sóng biến dạng lần lượt là $3,96 \mathrm{~m} / \mathrm{s}, 8,57 \mathrm{~m} / \mathrm{s}$ và $5,85 \pm 1,18 \mathrm{~m} / \mathrm{s}$.

Như vậy, ta có thể dễ dàng nhận thấy rằng, vận tốc sóng biến dạng trung bình của các tổn thương lành tính thấp hơn nhiều so với tổn thương ác tính. Điều này cũng chứng tỏ rằng các tổn thương ác tính sẽ cứng hơn các tổn thương lành tính. Số liệu của chúng tôi phù hợp với các tác giả này:

+ Nghiên cứu của Tang Li (2015) có kết quả: giá trị trung bình vận tốc sóng biến dạng của tổn thương lành tính, ác tính lần lượt là 3,10 \pm $1,02 \mathrm{~m} / \mathrm{s}$ và $5,89 \pm 1,92 \mathrm{~m} / \mathrm{s}[8]$.

+ Tác giả Xiao Long Li (2016), giá trị trung bình vận tốc sóng biến dạng của tổn thương lành tính, ác tính lần lượt là $2,91 \pm 0,87 \mathrm{~m} / \mathrm{s}$ và 5,20 $\pm 1,85 \mathrm{~m} / \mathrm{s}$ [9].

- Ngướng giá trị tham chiếu vận tốc sóng biến dạng

Từ số liệu vận tốc sóng biến dạng của khối u vú, chúng tôi có biểu đồ 2 về đường cong ROC. Diện tích dưới đường cong ROC (AUC) là 0,997.

Khi tăng ngưỡng vận tốc sóng biến dạng thì độ đặc hiệu tăng, nhưng độ nhạy lại giảm. Chúng tôi đưa ra vận tốc sóng biến dạng của tổn thương ở ngưỡng cắt $3,79 \mathrm{~m} / \mathrm{s}$ có độ nhạy $(100 \%)$ và độ đặc hiệu $(95,7 \%)$ cao nhất trong chẩn đoán u vú ác tính.

Nghiên cứu của tác giả Tang Li (2015) đưa ra ngưỡng cắt vận tốc sóng biến dạng của tổn thương lành tính, ác tính ở mức $3,68 \mathrm{~m} / \mathrm{s}$ có độ nhạy 93,3\%, độ đặc hiệu 79,4\%. Diện tích dưới đường cong ROC là 0,942 [8].

Tác giả Xiao Long Li và cộng sự (2016) cho kết quả ngưỡng cắt vận tốc sóng biến dạng của tổn thương lành tính, ác tính ở mức $3,49 \mathrm{~m} / \mathrm{s}$ có độ nhạy $87,2 \%$, độ đặc hiệu $82,6 \%$, độ chính xác $84,5 \%$. Diện tích dưới đường cong ROC là 0,907 [9].

Qua nghiên cứu này, chúng tôi cũng thây rõ một điều như nhiều tác giả trước đây đã nhận định: giá trị ngưỡng phát hiện bệnh của vận tốc sóng biến dạng ở tổn thương u vú có sự khác nhau ở mỗi quốc gia, dân tộc. Do đó việc xây dựng một giá trị tham chiếu vận tốc sóng biến dạng đảm bảo tối ưu nhất cho việc chẩn đoán ung thư vú là rất cần thiết. Tại Bệnh viện Phụ sản Hải Phòng, ngưỡng giá trị vận tốc sóng biến dạng của tổn thương là $3,79 \mathrm{~m} / \mathrm{s}$ sẽ có độ nhạy $(100 \%)$ và độ đặc hiệu $(95,7 \%)$ cao nhất trong chẩn đoán u vú ác tính.

\section{KẾT LUẬN}

Vận tốc sóng biến dạng trung bình của các tổn thương lành tính là $2,61 \pm 0,52 \mathrm{~m} / \mathrm{s}$ và ác tính là $5,85 \pm 1,18 \mathrm{~m} / \mathrm{s}$. GIá trị này ở ngưỡng tham chiếu $3,79 \mathrm{~m} / \mathrm{s}$ có độ nhạy $100 \%$ và độ đặc hiệu $95,7 \%$ cao nhất trong chẩn đoán ung thư vú tại Bệnh viện Phụ sản Hải Phòng.

\section{KHUYẾN NGH!}

Siêu âm đàn hồi sóng biến dạng (SWE) hứa hẹn là kỹ thuật có độ nhạy, độ đặc hiệu cao trong chẩn đoán các tổn thương vú, rất hữu ích trong việc phân biệt tổn thương ác tính và lành tính của tuyến vú. Tuy nhiên kỹ thuật này còn mới ở nước ta. Cần có những nghiên cứu với cõ mẫu lớn hơn để tăng giá trị chẩn đoán.

\section{TÀl LIỆU THAM KHẢO}

1. American Cancer Society (2017), Breast Cancer Facts \& Figures 2017-2018.

2. Cosgrove DO, et al. (2012), "Shear wave elastography for breast masses is highly reproducible", European radiology. 22, pp. 1023-1032.

3. Globocan (2012), "Fast Stats. Most frequent cancers".

4. Itoh, Ako, et al. (2006), "Breast disease: clinical application of US elastography for diagnosis", Radiology. 239(2), pp. 341-350.

5. Lan, NguyenH, Laohasiriwong, Wongsa (2013), "Survival probability and prognostic factors for breast cancer patients in Vietnam", Global health action. 6(1), p. 18860.

6. Lee, Su Hyun, et al. (2014), "Practice guideline for the performance of breast ultrasound elastography", Ultrasonography. 33(1), p. 3.

7. Schaefer FKW and Heer I (2011), "Breast 
ultrasound elastography-results of 193 breast lesions in a prospective study with histopathologic correlation", European journal of radiology. 77(3), pp. 450-456.

8. Tang, Li, et al. (2015), "A novel two-dimensional quantitative shear wave elastography for differentiating malignant from benign breast lesions", International journal of clinical and experimental medicine. 8(7), p. 10920.

9. Xiao Long Li , et al (2016), "Value of Virtual Touch Tissue Imaging Quantification for Evaluation of Ultrasound Breast Imaging-Reporting and Data System Category 4 Lesions", Ultrasound Med Biol. 42(9), pp. 2050-7.

\title{
ĐÁNH GIÁ TÌNH TRANG VÀ NHU CẦU CHĂM SÓC SỨC KHỎE CỦA NGƯỜI CAO TUỔI TẠI TỈNH THỪA THIÊN HUẾ
}

\author{
Võ Văn Thắng1,2, Võ Nữ Hồng Đức'1, \\ Lương Thanh Bảo Yến ${ }^{1,2}$, Vũ Thị Cúc ${ }^{1}$, Nguyễn Phúc Thành Nhân ${ }^{2}$
}

TÓM TẮT

Mục tiêu: Mô tả tình trạng chức năng, tiếp cận dich vư chăm sóc sức khỏe và xác đinh nhu cầu chăm sóc sức khỏe của người từ 60 tuổi trở lên tại tỉnh Thừa Thiên Huế. Phương pháp: Nghiên cứu mô tả cắt ngang tiến hành từ tháng 6/2018 đến tháng 6/2019 trên 932 người từ 60 tuổi trở lên đang sinh sống trên 3 vùng sinh thái thuộc địa bàn tỉnh Thừa Thiên Huế bằng hình thức phỏng vấn. Kết quả: 932 người cao tuổi từ 60 trở lên với độ tuổi trung bình là $72,71 \pm$ 6,64 . $29,1 \%$ người cao tuổi gặp các vấn đề về suy giảm nhận thức, Chức năng thị giác (nhìn), thính giác (nghe) càng suy giảm ở độ tuổi càng cao. Tăng huyết áp và các bệnh về cơ xương khớp là các bệnh phổ biến nhất ở người cao tuổi. $89,2 \%$ người cao tuối sử dụng các dịch vụ chăm sóc sức khỏe trong 3 năm gân đẩy, các cở sở Y tế công lập như Bệnh viện công, trạm Y tế là các cơ sở được sử dung nhiều. Nhu cầu kiểm tra sức khỏe định kỳ, nhu cầu chăm sóc sức khỏe tại nhà và nhu cầu tư vấn thông tin sức khỏe là 3 nhu cầu cao nhất ở người cao tuổi được phỏng vấn. Kết luân: Nghiên cứu cho thấy thực trạng sức khỏe cũng như suy giảm chức năng và tình trạng khuyết tật (ghi nhớ, nhìn, nghe và đi lai) ở người cao tuổi trền đia bàn tỉnh Thừa Thiên Huế. Đối tượng có nhu cầu khá cao về chăm sóc sức khỏe với xu hướng già hóa dân số hiện nay. Nhu câu chăm sóc phù hợp với bối cảnh văn hóa, nên được quan tâm hơn, về chính sách cho người cao tuổi ở Việt Nam.

Tư khóa: Người cao tuổi, nhu câu, chăm sóc sức khỏe, suy giảm chức năng.

\section{SUMMARY}

ASSESSMENT OF THE HEALTH STATUS AND HEALTHCARE NEEDS OF ELDERLY PEOPLE IN THUATHIEN-HUE PROVINCE

\footnotetext{
${ }^{1}$ Trường Đai hoc Y Dước Huế

2Viện Nghiên cứu Sức khỏe Cộng đồng, Trường Đại hoc Y Dược Huế

Chiu trách nhiệm chính: Võ Văn Thắng

Email: vovanthang147@hueuni.edu.vn

Ngày nhận bài: 18.11.2020

Ngày phản biên khoa họ: 24.12.2020

Ngày duyệt bài: 4.01.2021
}

Objectives: To describe the functional status and accessibility to health care services and to identify the healthcare demand among people aged 60 years and older in Thua Thien Hue province. Methods: A crosssectional study was conducted from June 2018 to June 2019 on 932 people aged 60 and older who were living in 3 ecological regions in Thua Thien Hue province by face to face interviews. Results: The average age of 932 people aged 60 and older was $72.71 \pm 6.64$. $29.1 \%$ reported cognitive impairment; visual and auditory function deteriorates with age. Hypertension and musculoskeletal diseases were the most common diseases among the elderly. $89.2 \%$ of the elderly have used health care services in the last 3 years; public health facilities such as public hospitals and commune health centers were used a lot. The need for periodic health checks, the need for home health care, and the need for health information counseling were the three highest needs among the elderly. Conclusions: The study showed the health status as well as the functional impairment and disability (memory, vision, hearing and walking ability) among the elderly and their healthcare needs in Thua Thien Hue province. The older people had a relatively high healthcare demand at the current trend in aqing population. Their demand for cultural- specific healthcare should be increasingly prioritized for aging care policy in the country.

Keywords: Elderly, needs, health care, functional impairment.

\section{I. Đă̆T VẤN ĐỀ}

Việt Nam là quốc gia có tốc độ già hóa dân số nhanh trên thế giới. Già hóa dân số kéo theo sự thay đổi trong mô hình bệnh tật, cơ sở hạ tầng và các dịch vụ an sinh xã hội, và nhu cầu sử dụng các dịch vụ hỗ trợ cho người cao tuổi (NCT). Cùng với sự già hòa dân số, quy mô hộ gia đình ở Việt Nam cũng có sự thay đổi rõ rệt. Mô hình gia đình nhiều thế hệ dần dần được thay thế bằng gia đình hạt nhân với chỉ có bố me và con cái. Sự di cư từ nông thôn lên thành thị của người trong độ tuổi lao động góp phần làm tăng tỷ lệ người cao tuổi sống một minh và tỷ lệ gia đình khuyết thế hệ ở nông thôn (gia đình chỉ 